\title{
FUNGSI TORTOR PARSIARABU DI DESA SALAON KECAMATAN RONGGURNIHUTA KABUPATEN SAMOSIR
}

\author{
MAGDALENA DINA SIFRA
}

Prodi Pendidikan Tari

\begin{abstract}
This study discusses the function of the Parsiarabu in the village of Salaon Tortor Subdistrict Rongurnihuta Samosir Regency.Landasan teoritis yang digunakan dalam penelitian in] yaitu Teori Fungsi menurut Danesi.

The theoretical foundation that is used in this study i.e. the theory of Function according to Danesi people who live in the village of Salaon sub-district of Ronggurnihuta Samosir Regency. Data collection is done by the method of field work which includes some steps i.e. interview, direct observation, documentation and library studies. The methods used in the research is qualitative, descriptive methods.

Research results based on the data collected can be known that Tortor Parsiarahu is the life story of Batak Toba at partonun on Samosir formerly, especially wives who had left her husband and wife where the husband lost when taking of arabu ulos dye in the forest. From there it became a habit for a group of masyarakatan partonun in one village where each host na mabalu (the wife who had lost husbands) then the family whose husband died will hold the manortor Parsiarabu where Tortor is the wife who has lost her husband to entertain their friends who recently lost her husband in order to rise from sorrow.
\end{abstract}

Keywords: Function, Tortor Parsiarabu 


\section{PENDAHULUAN}

Sumatera Utara merupakan salah satu provinsi di Indonesia yang memiliki kebudayaan yang berbedabeda yang dilatarbelakangi oleh delapan etnis yaitu : Batak Toba, Batak Karo, Batak Simalungun, Batak Mandailing, Pakpak Dairi, Sibolga, Melayu dan Nias, sehingga membuat Provinsi ini memiliki hasil budaya yang banyak serta mengandung norma-norma dan nilainilai kehidupan yang berlaku dalam tata pergaulan masyarakat yang bersangkutan. Menurut Dikson (1928:27) mematuhi norma-norma serta menjunjung nilai-nilai sangat penting bagi masyarakat itu sendiri dalam melestarikan kehidupan berbudaya dan bermasyarakat.

Suku Batak Toba sebagai salah satu suku yang terdapat di Sumatera Utara memiliki kebudayaan yang mengatur kehidupan mereka, sejak lahir hingga meninggal, seperti yang terdapat pada Suku Batak Toba yang berada di Samosir khususnya di Desa Salaon Kecamatan Ronggurnihuta

Kabupaten Samosir. Mereka masih menjaga warisan dari leluhur dan nenek moyang terdahulu sebagai upaya untuk melestarikannya. Dalam hal ini, hasil kesenian yang merupakan bagian dari kebudayaan dan jarang terdengar oleh masyarakat luar adalah tentang Tortor Parsiarabu. Tortor Parsiarabu adalah tradisi yang pernah hidup pada masyarakat Batak Toba sejak zaman dahulu. Parsiarabu adalah sebuah cerita yang sudah terlupakan dari kisah kehidupan para "Partonun" (penenun ulos) di Tanah Batak. Tortor Parsiarabu merupakan Tortor pada acara kematian dengan tujuan menghibur. Tortor Parsiarabu dilakukan oleh para istri yang sudah ditinggal pergi (meninggal) oleh suaminya di rumah duka untuk menghibur seorang istri yang baru saja kehilangan suaminya. Yang dalam bahasa batak disebut Monding, Tortor ini merupakan wujud ekspresi kesedihan para istri karena ditinggalkan suaminya untuk selama - lamanya. Parsiarabu berasal dari imbuhan par - arabu, par artinya orang dan arabu adalah sejenis pohon yang menghasilkan warna untuk ulos, jadi Parsiarabu adalah orang yang mengambil warna 
ulos. Tortor Parsiarabu yang menceritakan kesedihan istri karena kehilangan suaminya saat mencari arabu (pewarna ulos) di hutan, melakukan "mangandungi" (menangis sambil mengingat kenangan tentang almarhum suami). Tarian ini bertujuan untuk menghantarkan doa-doa dan harapan dibalik ulos yang dipakai sebagai tujung (ulos yang dikepala) dimana ulos sebagai media untuk menutupi rasa kesedihan namabalu (istri yang baru ditinggal suami) tersebut agar air mata dan kesedihan tidak terlihat.

Berdasarkan uraian di atas, maka peneliti tertarik mengangkat tari ini menjadi topik penelitian untuk memperoleh penjelasan yang lebih dalam tentang fungsi Tortor Parsiarabu. Oleh karena itu, topik penelitian dengan judul : "Fungsi Tortor Parsiarabu di Desa Salaon Kecamatan Ronggurnihuta

Kabupaten Samosir”.

\section{Landasan Teori}

Untuk membahas Fungsi

Tortor Parsiarabu di Desa Salaon Kecamatan Ronggurnihuta penulis menggunakan teori Fungsi dari Danesi.

\section{Lokasi dan Waktu Penelitian \\ Tempat dilaksanakannya penelitian adalah di Desa Salaon Kecamatan Ronggurnihuta.}

\section{Populasi dan Sampel}

Populasi dan sampel dalam penelitian ini berjumlah tiga orang yaitu narasumber, tokoh adat, dan seniman.

\section{Teknik Pengumpulan Data}

Teknik pengumpulan data yang dilakukan adalah sebagai berikut:

1. Observasi

2. Wawancara

3. Dokumentasi

4. Studi kepustakaan

\section{Teknik Analisis Data}

Penulis menganalisa dan menguraikan data-data tersebut dengan menggunakan teknik penelitian kualitatif yaitu sebagai prosedur pemecahan masalah yang diselidiki dengan menggambarkan 
keadaan objek penelitian pada saat sekarang Kabupaten Samosir. Waktu yang digunakan dalam penelitian ini untuk mendapatkan data dibutuhkan adalah selama tiba bulan yang akan dilaksanakan pada November 2015 sampai Februari 2016.

\section{ISI}

\section{Gambaran Umum}

\section{Letak Geografis Kabupaten} Samosir terletak pada $2024^{\prime}$ - $2025^{\prime}$ Lintang Utara dan 980 21` - 990 55‘ BT. Kabupaten Samosir terletak di wilayah dataran tinggi, dengan ketinggian antara $904-2.157$ meter di atas permukaan laut, dengan topografi tanah yang beraneka ragam yaitu datar, landai, miring dan terjal. Struktur tanahnya labil dan berada pada wilayah gempa tektonik dan vulkanik. Kabupaten Samosir tergolong ke dalam daerah beriklim tropis basah dengan suhu berkisar antara 17 OC - 29 OC dan rata-rata kelembapan udara 85,04 persen. Jenis Tanah Topografi dan kontur tanah di Kabupaten Samosir pada umumnya berbukit dan bergelombang. Penggunaan Lahan Kabupaten Samosir memiliki 10 buah sungai yang keseluruhannya bermuara ke Danau Toba. Sebahagian dari sungai tersebut telah dimanfaatkan untuk mengairi lahan sawah seluas 3.987 ha, lahan sawah yang beririgasi setengah teknis $(62,13 \%$ dari luas yang ada). Panjang saluran irigasi di Kabupaten Samosir mencapai $74,77 \mathrm{~km}$, terdiri dari irigasi setengah teknis 70,63 km $(21,53 \mathrm{~km}$ saluran primer dan 49,10 $\mathrm{km}$ saluran sekunder) dan irigasi sederhana $4,14 \mathrm{~km}$.

Luas lahan produktif di Kabupaten Samosir (2002) mencapai 69.798 ha, terdiri dari lahan sawah 7.247 ha $(10,4 \%)$, dan lahan kering 62.551 ha $(89,6 \%)$. Terbatasnya sarana irigasi, modal dan tenaga kerja kasar mengakibatkan hanya 14.110 ha $(22,56 \%)$ lahan kering yang dikelola. Selebihnya merupakan lahan tidur seluas 48.441 ha atau $77,44 \%$ dari lahan kering yang dapat dikelola.

Wilayah Kabupaten Samosir Luas wilayah Kabupaten Samosir secara keseluruhan mencapai 254.715 Ha, terdiri dari daratan seluas $144.455 \mathrm{Ha}$ dan perairan danau seluas 110.260 Ha. Luas dan 
batas perairan di kawasan Danau Toba belum ada ketentuan yang pasti. Namun mengingat Pulau Samosir tepat berada dan dikelilingi oleh Danau Toba, secara proporsional luas perairan Danau Toba yang menjadi bahagian daerah Kabupaten Samosir.

\section{Mata Pencarian}

Dahulunya Masyarakat Batak Toba mata pencahariannya adalah sebagai petani. Para ibu rumah tangga martonun (menenun ulos), namun seiring majunya zaman dan tingkat kebutuhan yang tinggi banyak penduduk Samosir mulai beralih profesi sebagai nelayan kerambah didukung dengan wilayah Kabupaten Samosir yang dikelilingi danau sehingga sangat memungkinkan pekerjaan ini memiliki banyak keuntungan. Namun masih banyak juga sumber daya alam yang bermanfaat dan menjadi mata pencaharian masyarakat setempat yaitu sektor perkebunan, peternakan, perikanan.

Perempuan Batak di wilayah Kabupaten Samosir selain memanfaatkan hasil alam juga mengambangkan industri kerajinan khususnya kerajinan tenun ulos sebagai mata pencaharian sampingan. Kebiasaan tersebut yang membuat perempuan umumnya pintar menenun ulos dikarenakan kegiatan ini diwariskan secara turun temurun dari generasi ke generasi. Dari kebiasaan perempuan Batak yang pada umumnya ibu rumah tangga bertenun ulos, dari sanalah muncul Tortor Parsiarabu yang menceritakan bagaimana kisah kehidupan partonun (penenun) setelah ditinggal mati oleh suaminya. Dimana ibu rumah tangga yang telah ditinggal mati oleh suami agar bangkit dari rasa keterpurukan, maka sebagai sesama istri yang telah ditinggalkan mati oleh suami datang manortor (menari) untuk menghibur teman mereka yang baru kemalangan ditinggal mati suami.

\section{Asal Usul Tortor Parsiarabu}

Tortor Parsiarabu yang artinya Tortor adalah tari dalam adat Batak, dan Parsiarabu berasal dari imbuhan par - arabu, par artinya orang dan arabu artinya pohon untuk menghasilkan warna ulos, jadi parsiarabu adalah orang yang 
mengambil warna ulos. Tortor

Parsiarabu adalah bagian dari upacara monding Hatungganeon untuk janda yang mabalu (baru kehilangan suami) yang dimana dalam upacara ini masih ada upacara adat dan disana para istri yang telah kehilangan suami akan manortor Parsiarabu dengan tujuan untuk menghibur teman mereka yang baru kehilangan suami, dimana mereka ikut merasakan kesedihan yang dirasakan keluarga yang baru kemalangan, dan dahulu nya ini sering diadakan untuk masyarakat dikalangan partonun (penenun).

\section{Ragam Gerak Tortor Parsiarabu}

Menerbang Ulos

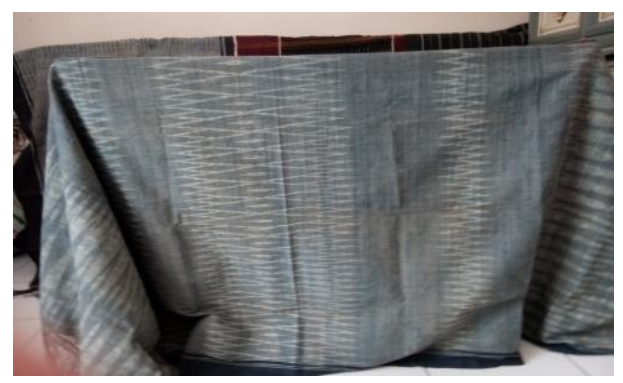

Mamake Tujung

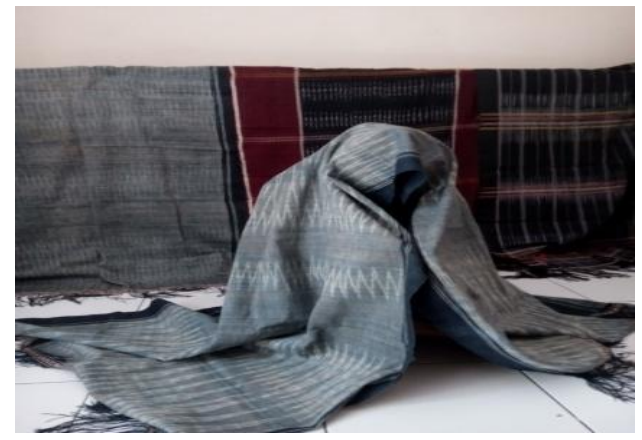

Menghapus Ilu

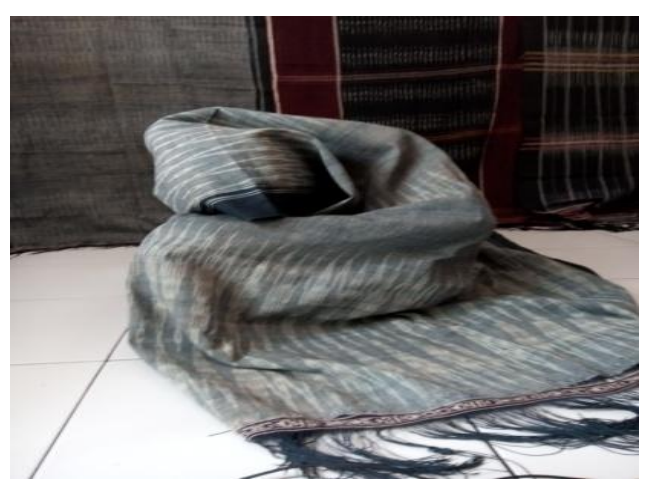

Somba 


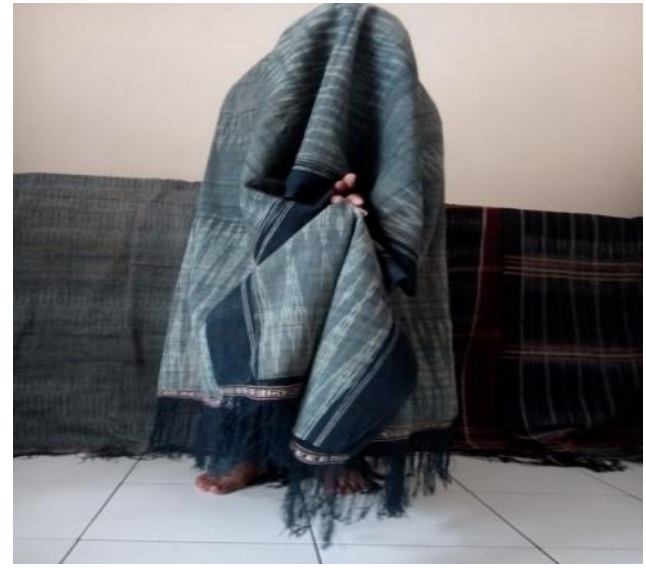

Manerbang Ulos

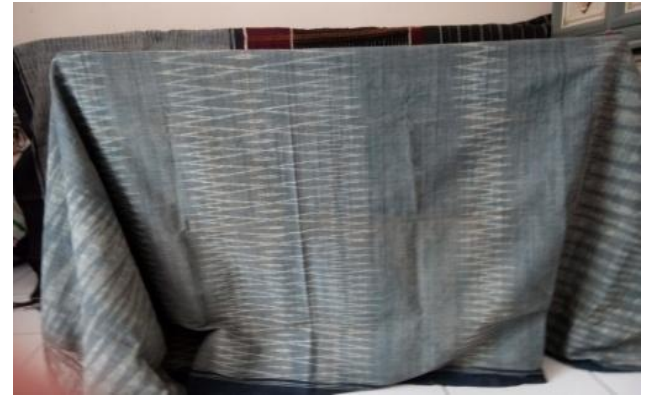

Malopit Ulos

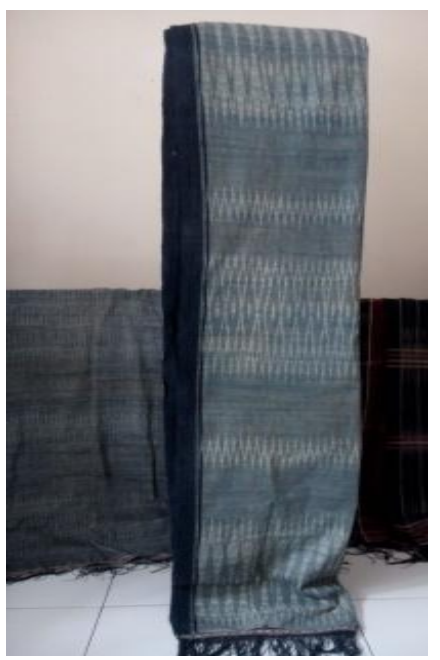

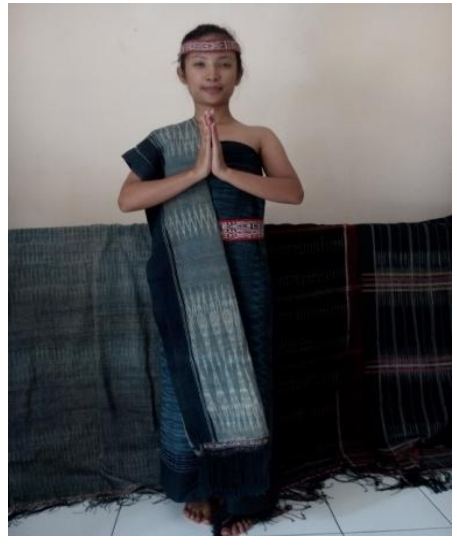

Pandenggal

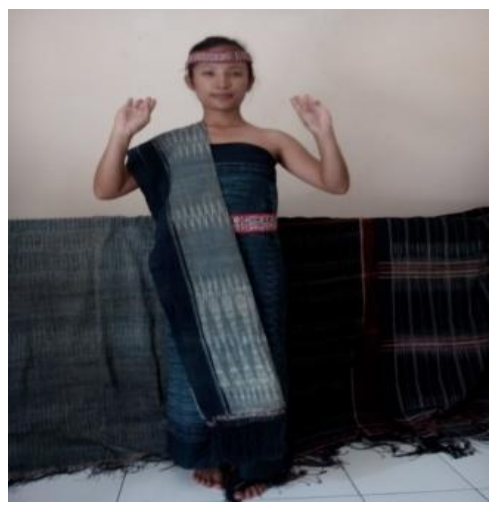

Pangembas

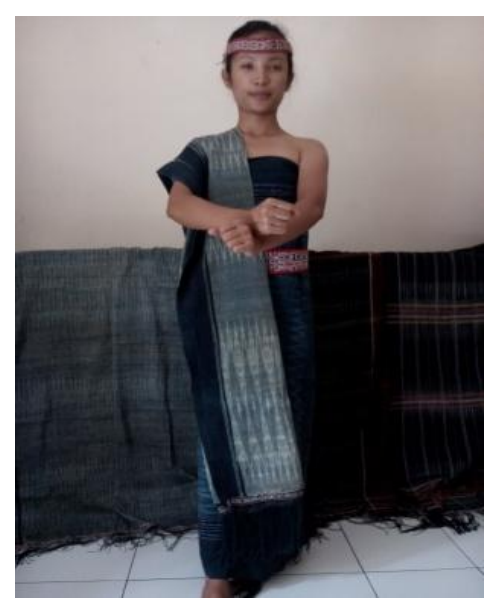

Somba 


\section{Fungsi Tortor Parsiarabu}

\section{Tortor Parsiarabu menjadi} bentuk komunikasi estetis

Tortor Parsiarabu menjadi bentuk komunikasi estetis karena gerak-geraknya mengekspresikan emosi dan suasana hati yang sedih dan berduka sebagai akibat ditinggal mati oleh suami saat mencari arabu (pewarna ulos) di hutan. Pekerjaan di hutan mengandung bahaya yang cukup besar diakibatkan hutan di daerah Samosir yang jauh di atas gunung dan masih dipenuhi binatang buas sehingga bahaya yang harus dihadapi para suami cukup besar. Dengan demikian kematian suami karna mencari arabu (pewarna ulos) di hutan sangat menyedihkan hati istri yang ditinggalkan. Kesedihan tersebut diekspresikan dan dikomunikasikan dengan menggunakan ulos sebagai media untuk menutupi rasa kesedihan istri tersebut agar air mata dan kesedihan tidak terlihat.
2. Tortor Parsiarabu menjadi bagian ritual dan berfungsi komunal

Tortor Parsiarabu muncul dari masyarakat yang dulu bekerja sebagai partonun. Tortor Parsiarabu tidak termasuk dalam bagian upacara keagamaan tetapi termasuk dalam upacara kematian hatungganeon dimana para istri yang telah kehilangan suaminya akan manortor Parsiarabu dengan tujuan menghibur teman mereka yang baru kehilangan suami, dimana mereka ikut merasakan kesedihan yang dirasakan keluarga yang baru kemalangan. Tortor Parsiarabu ini menjadi milik komunitas para janda yang bekerja sebagai partonun (penenun) untuk menghilangkan kesedihan dari istri yang baru ditinggal mati oleh suami sebagai wujud ikut merasakan kesedihan. Melalui Tortor Parsiarabu disampaikan rasa senasib sepenanggungan sebagai janda. 
3. Tortor Parsiarabu memainkan peran penting dalam fungsi sosial

Tortor

Parsiarabu

memainkan peran penting dalam fungsi sosial itu terlihat saat para istri yang telah kehilangan suami datang untuk menghibur teman mereka yang baru kehilangan suami, dimana mereka ikut merasakan kesedihan yang dirasakan keluarga yang baru kemalangan, dan dahulunya ini sering diadakan untuk masyarakat dikalangan partonun (penenun). Disamping untuk mengekspresikan rasa sedih dari istri yang telah kehilangan suami Tortor Parsiarabu juga berfungsi untuk menunjukkan empati sosial dari istri-istri yang lebih dahulu ditinggal mati oleh suami.

\section{PENUTUP}

\section{Kesimpulan}

Kebudayaan merupakan warisan dari leluhur yang sampai sekarang ini masih dilestarikan masyarakat. Tortor Parsiarabu merupakan warisan budaya dari masyarakat di Samosir yang berusaha untuk tetap dilestarikan sehingga menjadi ciri khas budaya itu sendiri dan menjadi kebanggaan tersendiri bagi masyarakat di Samosir. Berdasarkan uraian yang sudah dipaparkan dari Bab 1 sampai Bab IV dapat diketahui bahwa :

1. Tortor Parsiarabu merupakan tortor yang termasuk dalam upacara monding yaitu upacara kematian hatungganeon, karena istri yang kehilangan suaminya dahulunya rata-rata meninggal disaat telah memiliki anak-anak yang telah menikah namun belum mempunyai cucu. Tarian ini dahulunya hanya ditarikan oleh para istri yang telah ditinggal suaminya.

2. Asal - usul tortor Parsiarabu adalah martonun, dimana para wanita menenun ulos dan sang suami mencari pewarna ulos. Namun diperjalanan dalam mengambil warna ulos tersebut sang suami meninggal dunia, maka kesedihan yang mendalam dirasakan istri.

3. Fungsi tortor Parsiarabu ialah

a. tortor Parsiarabu tersebut menjadi bentuk komunikasiestetis Tortor Parsiarabu dapat menjadi 
bentuk komunikasi estetis yang mengepresikan emosi dan suasana hati karena mengisahkan tentang kesedihan hati seorang istri yang telah ditinggal mati oleh suami saat bekerja mencari arabu (pewarna ulos) di hutan mengandung resiko bahaya yang cukup besar, karena letak hutan di daerah Samosir yang jauh diatas gunung dan masih penuh dengan binatang buas, menyebabkan bahaya yang harus dihadapi para pencari arabu cukup besar. Dengan demikian kematian suami karna mencari arabu di hutan sangat menyedihkan hati istri yang ditinggalkan. Kesedihan tersebut diekspresikan dan dikomunikasikan dengan menggunakan ulos sebagai media untuk menutupi rasa kesedihan istri tersebut agar air mata dan kesedihan tidak terlihat.

b. menjadi bagian ritual dan berfungsi komunal

Tortor Parsiarabu muncul dari masyarakat yang dulu bekerja sebagai partonun. Tortor Parsiarabu tidak termasuk dalam bagian upacara keagamaan tetapi termasuk dalam upacara kematian hatungganeon dimana para istri yang telah kehilangan suaminya akan manortor Parsiarabu dengan tujuan menghibur teman mereka yang baru kehilangan suami, dimana mereka ikut merasakan kesedihan yang dirasakan keluarga yang baru kemalangan.

c. memainkan peran penting dalam fungsi sosial

Tortor Parsiarabu memainkan peran penting dalam fungsi sosial itu terlihat saat para istri yang telah kehilangan suami datang untuk menghibur teman mereka yang baru kehilangan suami, dimana mereka ikut merasakan kesedihan yang dirasakan keluarga yang baru kemalangan, dan dahulunya ini sering diadakan untuk masyarakat dikalangan partonun. 
Saran

Desa Salaon Kecamatan Ronggurnihuta Kabupaten Samosir termasuk suku yang mempunyai keanekaragaman kesenian, namun banyak kesenian peninggalan nenek moyang dari suku Batak Toba tidak diketahui oleh generasi muda Batak Toba, bahkan tidak tahu sama sekali tentang kesenian daerahnya. Oleh karena itu penulis mengharapkan ada nya kesadaran dari seniman, masyarakat dan generasi muda Batak Toba, secara khusus kepada suku Batak Toba yang ada di Kabupaten Samosir :

1. Kepada generasi muda suku Batak Toba diharapkan lebih peduli dalam melestarikan peninggalan budaya dari leluhur yang perlu dipublikasikan ke dunia luar.

2. Kepada Dinas Pariwisata yang berfungsi sebagai menjaga kelestarian budaya salah satunya kesenian Tortor, sepatutnya agar memberikan perhatian khusus supaya tidak kehilangan identitas dari kebudayaan yang dimiliki.

3. Kepada Mahasiswa Universitas Negeri Medan Jurusan
Sendratasik Program Studi

Pendidikan Tari agar lebih mencintai dan melestarikan kebudayaan daerah, dan bisa menjadi acuan untukmeneliti kebudayaan Batak Toba di Kabupaten Samosir. 


\section{Daftar Pustaka}

Arikunto, Suharsimi, 2006. Prosedur

Penelitian Suatu Pendekatan

Praktik, Jakarta: Rineke Cipta

Azril, 2010. Bentuk Dan Gaya Penulisan Karya Tulisan Ilmiah. Jakarta: Universitas Trisakti

Aziz, Alimut Hidayat, 2007. Metode Penelitian Kebudayaan dan Teknik Analisis Data. Surabaya: Salemba Media

Danesi, M, 2004. Pesan, Tanda, dan Makna. Bandung

Dewi Rosmala, 2008. Metode Penelitian Kuantitaiif Kualitatif. Bandung: Penerbit Alfabeta

Ester, Debora. S, 2009. "Gondang Sebangunan pada Tortor Sigale-gale di Desa Tomok Kecamatan Simanindo Kabupaten Samosir". Skripsi Sendratasik, Universitas Negeri Medan

Hadi, Sutrisno, 2004. Metodologi Research Jilid 3. Yogyakarta: Andi, Hani, Ummi , dkk

Hariwijaya, M. dan Triton P. B, 2008. Pedoman Penulisan Ilmiah Proposal dan Skripsi.
Yogyakarta: Oryza, Hasan, Iqbal

Koentjaraningrat, 2006. Pengantar Antropologi. Jakarta. PT. Rineka cipta

Lindu, $\quad$ Simamora, 2011. "Perkembangan Gondang dan Tortor Sigale-gale di desa Tomok Kecamatan Simanindo Kabupaten Samosir”. Jurnal Sendratasik, Universitas Negeri Medan

Richard, Sinaga, 1999. Meninggal Adat Dalihan Natolu. Jakarta: Dian Utama dan Kerabat

Sarma, Sirait, 2008. "Tortor Dalam Upacara Kematian Saurmatua Pada Masyarakat Batak Toba". Skripsi Sendratasik, Universitas Negeri Medan

Sedyawati, Edi, 1986. Seni Pertunjukkan, Jakarta: Sinar Harapan

Sinta, Saron, 2008. "Tortor Parsiarabu di Kecamatan Harian Boho Kabupaten Samosir". Skripsi Sendratasik, Universitas Negeri Medan

Sugiono, 2008. Metode Penelitian Pendidikan, Bandung: Alfabeta 
Sugiono, 2009. Metode Penelitian

Bisnis

(Pendekatan

Kuantitatif, Kualitatif, dan

$R \& D$, Bandung: AlfaBeta

Sugiono, 2010. Metode Penelitian

Kuantitatif, Kualitatif dan

$R \& D$, Bandung: Alfabeta

Surakhmad, W. 1990. Metode Penelitian, Jakarta : Gramedia

Tylor, E.B. 1871. Primitif Culture. Jakarta: Gramedia

Yetty, S. 2010. "Perbedaan Peranan

Gondang pada Masyarakat Batak Toba Pada Acara Perkawinan dan Kematian". Skripsi Sendratasik, Universitas Negeri Medan 